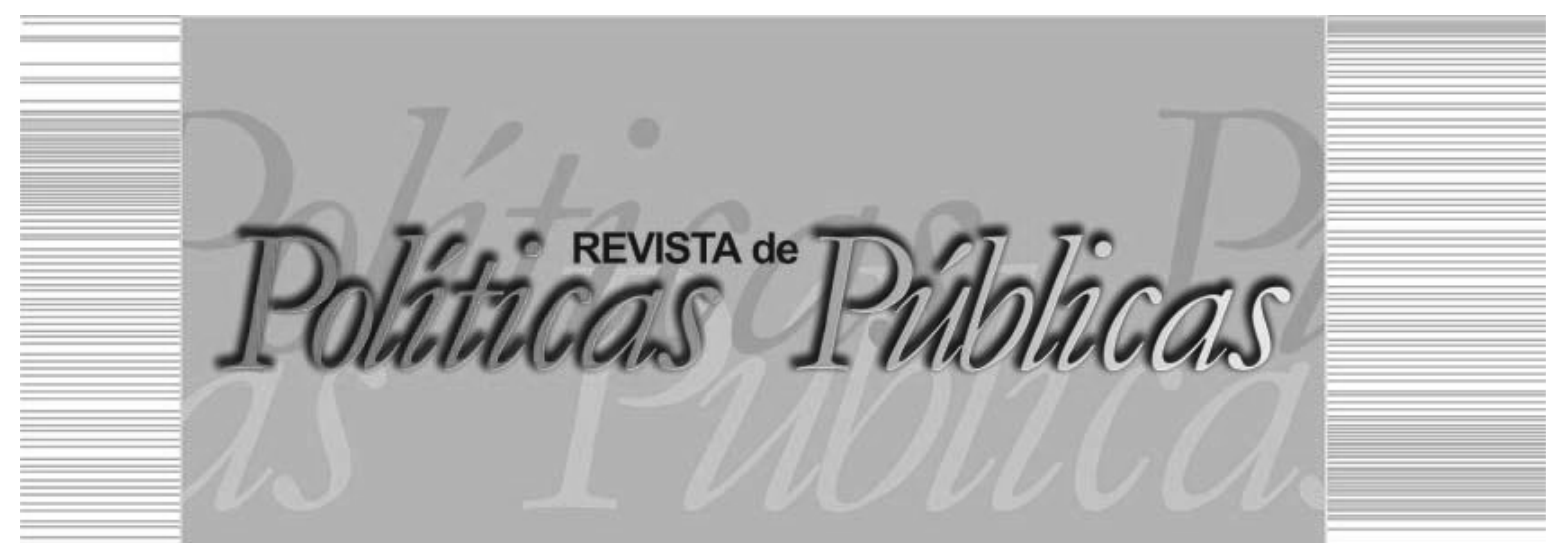

\title{
RAÇA E GÊNERO NO CAMPO PÚBLICO DE FOMENTO AO AUDIOVISUAL BRASILEIRO: mapeamento de policy makers
}

Eloiza Mara Silva ${ }^{1}$

\section{Resumo}

O objetivo deste trabalho é elaborar um quadro de "policy analysis" para a implementação de ações afirmativas na indústria audiovisual brasileira, levando em consideração três dimensões da política - institucional, processual e material. Nessa perspectiva, este estudo analisa a estrutura da Administração Pública Brasileira e delineia um mapa geral de diagnósticos, formuladores e políticas públicas anteriores com o objetivo de formular e implementar ações afirmativas de raça e gênero para a igualdade, a não discriminação e a distribuição justa de financiamento público para o desenvolvimento desse setor.

Palavras-chave: Ações afirmativas de gênero e raça; indústria audiovisual brasileira; políticas públicas

1 Bacharel em Direito, Especialista em Políticas Públicas pela Instituto de Economia (IE) da Universidade Federal do Rio de Janeiro (UFRJ), Servidora Pública Técnica Administrativo e Assessora da Superintendência de Análise de Mercado da Agência Nacional de Cinema (Ancine). E-mail: eloiza.silva@ancince.gov.br / Endereço: Agência Nacional de Cinema - Ancine: Escritório Central, Avenida Graça Aranha, n. 35, Centro, Rio de Janeiro - RJ. CEP: 20030-002 


\title{
RACE AND GENDER IN THE PUBLIC FIELD OF DEVELOPMENT TO BRAZILIAN AUDIOVISUAL: mapping
}

of policymakers

\begin{abstract}
The aim of this paper is to draw up a framework of "policy analysis" for the implementation of affirmative actions in Brazilian Audiovisual Industry, taking into account three dimensions of policy - institutional, procedural and material. From this perspective, this study analyses the structure of the Brazilian $\mathrm{Pu}$ blic Administration and delineates a general map of diagnoses, policymakers, and previous policies with of the objective the formulation and implementation of affirmative actions of race and gender for the equality, non-discrimination and fair distribution of public funding for the development of this sector.
\end{abstract}

Key words: Affirmative actions of gender and race, Brazilian Audiovisual Industry, public policies

\section{INTRODUÇÃO}

Publicações como o Infográfico Raça e Gênero no Cinema Brasileiro (2002-2014), elaborado pelo Grupo de Estudos Multidisciplinares das Ações Afirmativas (GEMAA) do Instituto de Estudos Sociais e Políticos (IESP) da Universidade Estadual do Rio de Janeiro (UERJ), têm trazido ao debate público expressivos dados de sub-representação ${ }^{1}$ da população negra. Entre as 20 (vinte) maiores bilheterias do cinema nacional, entre os anos de 2002 a 2014, nenhuma das funções de direção e de roteirização foi desempenhada por mulheres negras (CÂNDIDO; CAMPOS, 2016). Outras pesquisas do GEMAA (CÂNDIDO; CAMPOS; FERES JUNIOR, 2016) também apontam para a existência de um padrão na cinematografia brasileira, entre 1995 e 2014, que majoritariamente reforça um perfil do tipo branco, masculino e de classe média/alta, tanto atrás das câmeras (diretores, roteiristas, produtores executivos, entre outros) quanto na frente dessas (atores e atrizes).

Dessa forma, sinaliza que conteúdos audiovisuais difundidos nas salas de exibição do país têm representado frequentemente bens culturais homogêneos e pouco aderentes à realidade demográfica e sociocultural do Brasil: país majoritariamente negro e predominantemente feminino. Além disso, é possível apontar que o conjunto das obras audiovisuais massivamente fomentadas com recursos públicos também não tem sido capaz de refletir tal realidade social, 
especialmente, conjugando todas as interseccionalidades ${ }^{2}$ existentes entre gênero e raça.

Diante desse quadro, este artigo tem em vista as externalidades positivas que obras audiovisuais - bens culturais peculiarmente meritórios $^{3}$ - podem gerar na sociedade, tais como: multiplicidade de padrões estéticos e de costumes, representações simbólicas heterogêneas, pluralidade de narrativas, inclusão de grupos sociais não hegemônicos. Ademais, é considerado o proeminente papel do Estado enquanto principal indutor de políticas de fomento às produções audiovisuais, que atualmente se alicerçam sobre um fundo público destinado ao desenvolvimento e à sustentabilidade global de toda atividade audiovisual no Brasil: o Fundo Setorial do Audiovisual $(\text { FSA })^{4}$.

Com isso, a partir do ferramental teórico e prático que tem subsidiado a elaboração e execução de políticas públicas voltadas às ações afirmativas em outros campos de interesse público - a exemplo do sistema de cotas raciais no ensino superior - este artigo pretende esboçar uma análise de política pública policy analysis ${ }^{5}$, perpassando três dimensões da política - institucional, processual e material -, e delimitar um mapa geral (e não exaustivo) de policy makers (decisores públicos) que podem contribuir para implementação de políticas dessa natureza no audiovisual.

\section{AÇÕES AFIRMATIVAS NO ENSINO SUPERIOR E NO}

AUDIOVISUAL: conexões possíveis

\subsection{Ações afirmativas no campo do ensino superior público brasileiro: política pública de referência}

Qual política pública seria a mais adequada ao enfrentamento dos problemas levantados pelo GEMAA acerca da baixa diversidade na produção audiovisual nacional e da ausência de representação igualitária dos diferentes grupos sociais nas obras audiovisuais brasileiras, sobretudo das populações negra e feminina?

Preliminarmente a tal questão, é importante notar que existe ampla bibliografia sobre o campo de conhecimento denominado políticas públicas; por isso, é fundamental circunscrever suas características determinantes para, a partir disso, tratar das ações afirma- 
tivas enquanto agenda pública necessária e premente também no campo audiovisual brasileiro.

Por essa razão, em breve revisão de literatura, aponta-se Celina Souza (2006, p. 22), autora que retoma um pressuposto analítico central para pesquisa nesse campo: "[...] o de que em democracias estáveis, aquilo que o governo faz ou deixa de fazer é passível de ser (a) formulado cientificamente e (b) analisado por pesquisadores independentes". A partir disso, essa pesquisadora elenca conceituações possíveis de política pública, bem como autores de referência, sem a pretensão de revelar a melhor definição. Perspectiva epistemológica que também influencia o presente artigo.

Dentre os textos de autores que sedimentaram as bases epistemológicas desse campo, conforme apontado por Souza (2006), foram consultados os originais e as respectivas conceituações de política pública, a saber: de Lawrence M. Mead (1995, p. 1) "I see public policy as an approach to the study of politics that analyzes government in the light of major public issues"; de Thomas R. Dye (1984, p. 1) "It is concerned with what governments do, why they do it, and what difference ir makes. [...] Public policy is whatever governments choose to do or not to do"; e, por fim, a ilustração de David Easton (1957, p. 384) exemplificando seu modelo de political system gerador de ações por parte dos governos (policies).

Figura 1 - Political Sytem de David Easton

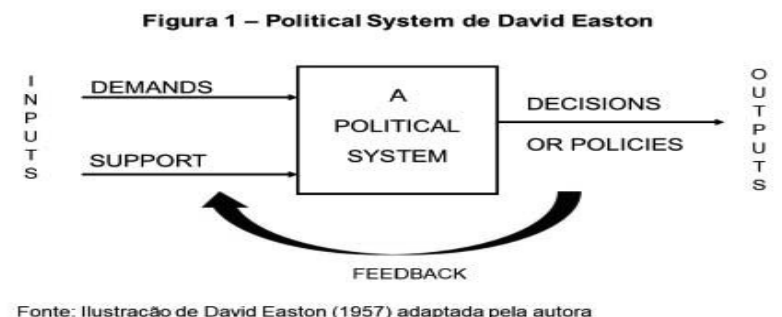

Fonte: Adaptada pela autora, conforme ilustração de: EASTON, D. An approach to the analysis of political systems. World Politics, [S. I.], v. 9, n. 3, pp. 383-400, apr. 1957. Disponível em: <https:// goo.gl/qjB3f7>. Acesso em: 1 mar. 2017.

A partir dessas premissas conceituais, é possível apontar que ações afirmativas em prol da promoção de igualdade material ${ }^{6}$ entre os mais diversos grupos sociais de uma mesma população que 
sofram discriminações negativas - sobretudo, em perspectiva interseccional entre opressões de raça e de gênero - são problemas e/ou demandas sociais de grande amplitude que consequentemente lançam um holofote sobre obrigações de fazer e de agir por parte dos governos.

Nesse sentido, se os policy makers devem fazer algo diante de problemas que afetam a coletividade, engajando-se na formulação de soluções para questões que tenham entrado na agenda pública, um desdobramento dessa tomada de posição seria localizar, entre as experiências de políticas públicas já implementadas pelos governos, um modelo de decisões político-administrativas policy cycle paradigmático e adequado à consecução das ações afirmativas.

Segundo Klaus Frey (2000), o chamado policy cycle é um modelo heurístico interessante para a análise do ciclo de vida de uma política pública, subdividindo o agir público em etapas parciais do processo político-administrativo de resolução de problemas: percepção e definição de problemas; agenda-setting; elaboração de programas e decisão; implementação de políticas; e, finalmente, avaliação de políticas e eventual correção da ação. Além disso, é importante destacar a observação de Frey (2000) de que esse modelo se trata de um tipo puro idealizador do processo político, servindo, portanto, de quadro de referência para a análise processual. Empiricamente, os atores sociais podem não se ater necessariamente a essa sequência e não hierarquizar essas etapas.

Considerado esse modelo, é possível afirmar que as ações afirmativas implementadas há mais de 15 anos no país - desde a promulgação da Lei Estadual do Estado do Rio de Janeiro $\mathrm{n}^{\circ} 3.708$, de 9 de dezembro de $2001^{7}$, regulamentada pelo Decreto $\mathrm{n}^{\mathrm{0}} 30.766$, de 04 de março de 2002 - são o projeto de política pública mais consolidado no país no que concerne às ações afirmativas, visto que percorreu cada uma dessas etapas parciais do policy cycle:

I - Percepção e definição de problemas: dentre as publicações de referência em pesquisa empírica sobre o racismo, que influenciaram as ações afirmativas no ensino superior brasileiro, é possível destacar os estudos qualitativos de Carlos Hasenbalg e Nelson do Valle Silva (décadas de 70 e 80) com relação à mobilidade social dos negros (OSÓRIO, 2004); a pesquisa de Luciana de Barros de Jaccoud e de Nathalie Beghin Desigualdades raciais no Brasil: um ba- 
lanço da intervenção governamental, publicado pelo IPEA em 2002; o Mapa da população negra no mercado de trabalho no Brasil, em 1999, realizado pelo Instituto Sindical Interamericano pela Igualdade Racial (INSPIR) do Departamento Intersindical de Estatística e Estudos Socioeconômicos (DIEESE), em 1999; Pesquisa Nacional de Amostra de Domicílios (PNAD), realizada em 1999;

II -Agenda-setting: Primeira Conferência Nacional contra o Racismo e a Intolerância, ocorrida no Rio de Janeiro, em julho de 2001; III Conferência Mundial contra o Racismo, a Xenofobia e as Intolerâncias Correlatas (Durban, África do Sul), realizada em 2001 e considerada um marco da luta antirracista internacional, que resultou em Declaração e Plano de Ação subscritos pelo Brasil;

III - Elaboração de programas e decisão: Programa Nacional de Diretos Humanos II (Brasil), realizado pelo Governo Fernando Henrique Cardoso (2002), cuja pauta englobava ações de promoção dos direitos da população negra no país; e criação da Secretaria Especial de Políticas de Promoção da Igualdade Racial (Seppir) pelo Governo Lula (2003), órgão que serviu de canal de diálogo entre Estado e o Movimento Negro (como o Geledés - Instituto da $\mathrm{Mu}$ lher Negra, o Educafro - Educação e Cidadania de Afrodescendentes e Carente, e Instituto de Advocacia Racial e Ambiental - IARA, entre outros);

IV - Implementação de políticas: programa específico de enfrentamento ao racismo e de promoção da igualdade racial incluído no Plano Plurianual de 2012-2015, que resultou na incorporação desses temas em outros 25 programas desse PPA, totalizando 121 metas, 87 iniciativas e 19 ações orçamentárias, em diferentes áreas governamentais; ; e amplo normativo federal, como é o caso do Estatuto da Igualdade Racial (Lei no 12.288, de 20 de julho de 2010), o qual prevê um conjunto de direitos destinado a garantir à população negra a efetivação da igualdade de oportunidades, inclusive por meio de programas e políticas de ação afirmativa em todos os campos da vida econômica, social, política e cultural do país (art. $4^{\circ}$, inciso II, Lei ${ }^{\circ}$ 12.288/2010). Cumpre notar que esse marco legal influen- 
ciou a implementação do regime de cotas em instituições de ensino superior e médio federais (Lei $\mathrm{n}^{\circ}$ 12.711, de 29 de agosto de 2012) e em concursos públicos para provimento de cargos efetivos e empregos públicos no âmbito da Administração Pública Federal (Lei no 12.990, de 9 de julho de 2014);

V - Avaliação de políticas: é vasto o campo de produção acadêmica sobre avaliação das ações afirmativas no ensino superior brasileiro, sendo possível destacar relatórios produzidos por instituições de ensino superior (IESs), tais como: Análise do Sistema de Cotas Para Negros da Universidade de Brasília , realizada pela Universidade de Brasília, em 2013; Avaliação Qualitativa dos Dados sobre Desempenho Acadêmico ${ }^{10}$, realizada pela Universidade Estadual do Rio de Janeiro, em 2011; além dos estudos do GEMAA de comparação entre ações afirmativas implementadas por IESs brasileiras;

VI - Eventual correção da política pública: no âmbito do Poder Judiciário esse sistema também já foi atestado como legítimo e constitucional no julgamento da Arguição de Descumprimento de Preceito Fundamental (ADPF) $n^{\circ}$ 186, no qual o STF decidiu pela constitucionalidade das cotas étnico-raciais na seleção de estudantes para a UnB, valendo-se de argumentos como: a compreensão da igualdade em seu duplo aspecto formal e material; a concreção da igualdade material (substancial) a todos os brasileiros, levando em consideração a diferença que os distingue por razões naturais, culturais, sociais, econômicas; e o de que o Estado, a fim de alcançar a igualdade material, pode formular políticas afirmativas, de modo que essas atinjam um grupo determinado, atribuindo-lhe certas vantagens por tempo limitado para que ele possa superar desigualdades históricas particulares.

Consideradas essas etapas, o policy cycle verificado em relação às ações afirmativas implementadas no ensino superior brasileiro habilita tais políticas públicas como marco teórico e prático maduro para policy makers, sociedade e governos, podendo servir de parâmetro para o tratamento de outras demandas sociais (inputs) e para geração de novas agendas públicas em outros campos. 


\subsection{Ações afirmativas no audiovisual brasileiro e inserção na agenda pública}

O policy cycle das ações afirmativas no ensino superior é referência devido à proximidade e às implicações históricas existentes entre o debate racial no campo da mídia audiovisual e no campo da educação. Segundo Joel Zito Araújo (2006, p. 75): “[...] o debate público hoje, em ambos os campos, continua baseado em pressupostos, ideias e fundamentos semelhantes". Pressupostos, ideias e fundamentos ancorados no chamado racismo institucional, estrutural ou sistêmico, que, de acordo com o Programa de Combate ao Racismo Institucional (apud GELEDÉS - INSTITUTO DA MULHER NEGRA, 2013, p.11), significa:

[...] o fracasso das instituições e organizações em prover um serviço profissional e adequado às pessoas em virtude de sua cor, cultura, origem racial ou étnica. Ele se manifesta em normas, práticas e comportamentos discriminatórios adotados no cotidiano do trabalho, os quais são resultantes do preconceito racial, uma atitude que combina estereótipos racistas, falta de atenção e ignorância. Em qualquer caso, o racismo institucional sempre coloca pessoas de grupos raciais ou étnicos discriminados em situação de desvantagem no acesso a benefícios gerados pelo Estado e por demais instituições e organizações.

Essa desvantagem também tem sido verificada no campo do audiovisual brasileiro e, atualmente, debatida a partir de matérias jornalísticas. Em 06 de julho de 2014, a repórter da Agência Brasil, Isabela Vieira, com a lead As mulheres negras não estão nas telas de cinema, nem atrás das câmeras trouxe à tona a pesquisa $\mathrm{A}$ Cara do Cinema Nacional: gênero e cor dos atores, diretores e roteiristas dos filmes brasileiros (2002-2012). Essa notícia repercutiu em vários veículos, em redes sociais, bem como, em páginas eletrônicas de entidades da sociedade civil, como o Geledés, porque difundiu dados expressivos acerca da baixa representatividade negra e feminina. Nas telas, atrizes negras (pretas e pardas) corresponderam a 4,4\% do elenco principal desses filmes nacionais e nenhum desses filmes contou com a direção e/ou roteirização de mulheres negras.

Se diagnósticos desse tipo são amplificados pelo debate público e, paradoxalmente, são silenciados ou omitidos em processos de nondecision-making ${ }^{11}$ por parte de governos - sobretudo, de países de trajetória colonial e escravocrata como o Brasil ${ }^{12}$, isso expõe o fracasso, a insuficiência ou a ausência de implementação de políticas 
públicas por parte de agentes públicos. Logo, se o Estado não age, isso pode naturalizar e perpetuar essa sub-representação na sociedade em descompasso com a magnitude e a urgência desse problema social.

Nas políticas setoriais para o audiovisual brasileiro, esse descompasso se torna mais acentuado na medida em que se verifica expressivo volume de recursos públicos no FSA, o qual poderia englobar políticas públicas voltadas às ações afirmativas. De acordo com a Agência Nacional do Cinema (Ancine), cerca de 1 bilhão de reais desse fundo público foram investidos na cadeia de valor do audiovisual brasileiro (produção, distribuição e exibição/veiculação) entre 2008 e $2014^{13}$.

A despeito da efetividade dos governos para utilizar esses recursos e enfrentar essa sub-representação no campo do audiovisual, esses diagnósticos vêm alcançando projeção no país e mobilizando outras vozes na opinião pública. Essa questão também tem sido vocalizada pelos próprios realizadores negros e negras: como Joel Zito Araújo, no Documentário A Negação do Brasil (2000) e no artigo A força de um desejo: a persistência da branquitude como padrão estético audiovisual (2006); Jefferson De e Noel Carvalho, no manifesto Dogma Feijoada (2002); Yasmin Tainá, em entrevista ao jornal O Globo (FAUSTINI, 2015); e Viviane Ferreira (2015), em palestra no Festival Latinidades.

Destaca-se também o surgimento de novas entidades, como a criação de organização representativa de profissionais negros e negras desse setor por meio da fundação da Associação dos Profissionais do Audiovisual Negro (APAN), em dezembro de 2016, cuja importância é ressaltada por sua fundadora e presidenta, a realizadora Viviane Ferreira:

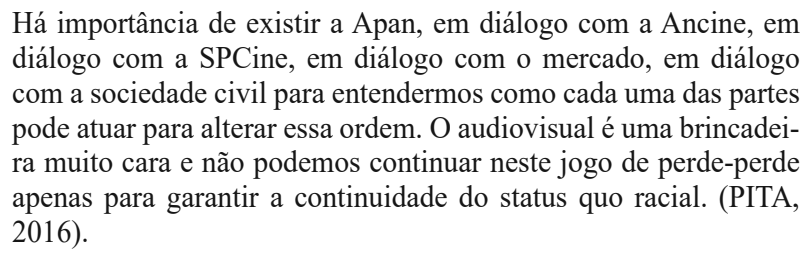

Há importância de existir a Apan, em diálogo com a Ancine, em diálogo com a SPCine, em diálogo com o mercado, em diálogo com a sociedade civil para entendermos como cada uma das partes pode atuar para alterar essa ordem. O audiovisual é uma brincadeira muito cara e não podemos continuar neste jogo de perde-perde apenas para garantir a continuidade do status quo racial. (PITA, 2016).

Assim, dado esse cenário de difusão de diagnósticos e de mobilização e organização de novos agentes, é possível apontar que o policy cycle de ações afirmativas no campo do audiovisual brasileiro 
está em curso e que, dado o atual estágio, poderá avançar e engajar órgãos e entes públicos responsáveis pela regulação e fomento do setor, em todo país, para tomada de decisão de enfrentamento efetivo e estrutural desse problema.

\section{MAPEAMENTO DE POLICY MAKERS PARA IMPLEMENTAÇÃO DAS AÇÕES AFIRMATIVAS NO AUDIOVISUAL BRASILEIRO}

No presente tópico serão relacionados os interlocutores públicos do tripé ${ }^{14}$ formado por entes do campo público da cultura que possuem prerrogativas de formulação, implementação e execução de políticas públicas de fomento estatal ao audiovisual em âmbito nacional: Conselho Superior do Cinema (CSC), SAv do Ministério da Cultura (MinC) e Ancine.

\subsection{Conselho Superior do Cinema (CSC)}

O CSC é um órgão colegiado, deliberativo e consultivo, criado pela Medida Provisória $\mathrm{n}^{\circ}$ 2.228-1, de 6 de setembro de 2001, sendo regulamentado pelo Decreto $\mathrm{n}^{\circ} 4.858$, de 13 de outubro de 2003. Ele integra a estrutura do MinC e tem por escopo a formulação e a implementação de políticas públicas para o desenvolvimento da indústria cinematográfica e audiovisual nacional. Trata-se, portanto, do principal órgão estatal da administração pública brasileira com poder de orientação e de tomada de decisões sobre esse setor, fixando diretrizes e metas de longo prazo, além de estar imbuído da premissa de ser um espaço de participação dos diversos setores dessa indústria e da sociedade civil. O quadro de conselheiros é composto por agentes públicos representantes de diversos órgãos de governo (Ministérios da Cultura, das Comunicações, da Fazenda, entre outros) e por representantes externos - seis especialistas em atividades cinematográficas e audiovisuais e três representantes da sociedade civil $^{15}$.

Dentre as principais competências, destacam - se os incisos I e VI do art. $1^{\circ}$ do supracitado Decreto: formulação da política nacional do cinema e do audiovisual e instituição de comitês e de grupos temático, de caráter permanente ou temporário, destinados ao estudo e elaboração de propostas sobre matérias específicas. Com base nessas prerrogativas, novos temas ${ }^{16}$ pertinentes ao segmento do audiovisual brasileiro estão sendo abordados de maneira ampla pelo CSC, tais 
como Video on Demand (VoD) e jogos eletrônicos (games). À vista disso, esses novos segmentos têm ocupado a agenda desse conselho e desencadeado o comando direto de que ações imediatas sejam realizadas por parte da Ancine, a exemplo do lançamento das seguintes consultas públicas em dezembro de 2016: Notícia Regulatória - Comunicação Audiovisual Sob Demanda e Análise de Impacto Regulatório: Jogos Eletrônicos. O que demonstra a capacidade desse órgão em partir do estágio de percepção e definição de problemas para os seguintes passos do chamado policy cycle: o de agenda-setting e o de elaboração de programas e decisão.

Conquanto essas não sejam temáticas de políticas públicas de ações afirmativas, elas auxiliam a compreensão da vida interna dos processos político-administrativos de domínio do CSC, demonstrando seu funcionamento institucional regular, assim como sua responsividade em relação a demandas organizadas por entidades, tais como a Associação Brasileira das Desenvolvedoras de Jogo Eletrônico (Abragames) e Associação Latino-americana de VOD (Alavod), entidades que possuem representantes designados como membros especialistas em atividades cinematográficas e audiovisuais do referido conselho, contando com mandato de dois anos, até 20 de dezembro de 2018.

Por conseguinte, essas experiências são capazes de sinalizar que se as demandas por ações afirmativas de raça e de gênero no campo do audiovisual brasileiro forem acolhidas pelo Conselho Superior do Cinema enquanto agenda setting urgente e necessária em sua pauta política atual, políticas públicas poderão ser formuladas e executadas pelos demais entes públicos desse tripé, Ancine e Secretaria do Audiovisual (SAv), no sentido de implementar tais ações ao longo de toda indústria audiovisual (produção, distribuição e exibição/veiculação).

\subsection{Secretaria do Audiovisual do Ministério da Cultura (SAv/ MinC)}

A SAv - órgão singular da administração direta vinculado ao Ministério da Cultura (MinC) - foi criada pela Lei 8.490, de 19 de novembro de 1992, durante o Governo Itamar Franco, simultaneamente à recriação do próprio MinC, como parte de um contexto de início de retomada de uma série de incentivos estatais no campo da cultura, incluindo o audiovisual ${ }^{17}$. Ao longo de quase uma década, a 
SAv foi a única instituição do Estado brasileiro focalizada no setor cinematográfico, sendo responsável pela definição das macropolíticas e pela implementação de programas e ações de fomento setorial.

Protagonismo que se modificou após a criação da Agência Nacional do Cinema (Ancine), em setembro de 2001. Momento no qual o então Presidente da República Fernando Henrique Cardoso transferiu algumas atribuições dessa secretaria para a Agência, além de ter reduzido o campo de influência do MinC em relação a esse novo ente regulador. (DA-RIN, 2010).

Por outro lado, durante o Governo Lula, a gestão do Ministro da Cultura Gilberto Gil ${ }^{18}$ propôs mudanças radicais em benefício da projeção de um papel ativo estatal na formulação e na implementação de políticas para a cultura. Dessa maneira, reposicionou o MinC enquanto articulador central da política para o audiovisual brasileiro ao lançar o Programa Brasileiro de Cinema e Audiovisual, um país de todas as telas, cujo objetivo foi o de elevar o audiovisual a tema estratégico do Estado brasileiro, além de integrar a Ancine entre suas entidades e órgãos vinculados e de alinhar ações entre essa Agência e a SAv. (BEZERRA, 2010).

Nesse contexto, uma concepção ampliada de cultura foi escolhida e difundida a fim de valorizar as seguintes dimensões desse campo: dimensão simbólica (diversidade de expressão e valores), dimensão de direitos e valores (inclusão social pela cultura) e dimensão econômica (geração de renda, empregos, regulação e fortalecimento dos processos produtivos da cultura).

Dentro dessa perspectiva, na esfera dessa Secretaria foram formuladas as primeiras iniciativas de editais nacionais focalizados na promoção de ações afirmativas. No que se refere à raça, isso se deu por meio do Edital de Apoio para Curta-Metragem - Curta Afirmativo: Protagonismo da Juventude Negra na Produção Audiovisual, que faz referência direta ao Estatuto da Igualdade Racial (Lei ${ }^{\circ}$ 12.288/2010), sendo formulado em conjunto com a Secretaria de Políticas de Ações Afirmativas da Secretaria de Políticas de Promoção da Igualdade Racial (SEPPIR) da Presidência da República (PR), que objetivou a seleção de 30 obras audiovisuais de curta-metragem dirigidos ou produzidos por jovens negros, de 18 a 29 anos, de temática livre, de ficção ou documentário, com valor individual para cada obra estimado em R $\$ 100$ mil. 
No que diz respeito a gênero, isso se viabilizou por meio do Edital Carmen Santos Cinema de Mulheres 2013, formulado em conjunto com a Secretaria de Políticas para as Mulheres da Presidência da República, que objetivou apoiar obras audiovisuais (10 curtas e 6 média-metragens) assinadas e dirigidas por mulheres, podendo perfazer os gêneros de ficção, documentário ou conter técnicas de animação, além de conter temática voltada à promoção da igualdade entre mulheres e homens, os direitos da mulher e a cidadania.

No decorrer do Governo Dilma, esse tipo de iniciativa de formulação de ações afirmativas sobre o campo do audiovisual permaneceu restrita a uma visão de nicho sobre essa temática, restando pontual e limitada às competências da SAv. Não sendo observadas, portanto, fortes interlocuções e compartilhamentos dessas políticas públicas em conjunto com o restante do tripé estatal de fomento ao setor - CSC e Ancine -, tampouco com os demais órgãos de governo, para que fosse possível abordar de maneira ampla e transversal o problema da sub-representação de gênero e de raça existente nesse setor.

Evidentemente, a crítica a esse enfoque governamental que trata a sub-representação como problema de nicho, excessivamente restrito às atribuições da SAv, não pretende anular a importância da existência dessas linhas de editais afirmativos, que são importantes marcos históricos na formulação de políticas públicas focalizadas em ações afirmativas por parte dos governos no Brasil. O que se observa problemático é que os policy makers do referido tripé estatal, até o momento, não foram capazes, nas etapas de percepção do problema, de agenda-setting e de elaboração de programas e de decisão, de terem uma visão ampliada e transversal para implementação de ações afirmativas, na qual se inclua o principal ente público federal de indução e de fomento do mercado audiovisual, a Ancine.

\subsection{Agência Nacional do Cinema (Ancine)}

A Ancine ${ }^{19}$ é uma autarquia especial, dotada de autonomia administrativa e financeira, e vinculada ao Ministério da Cultura, desde 2003. Instituída pela Medida Provisória n ${ }^{\circ} 2.228-1$, de 6 de setembro de 2001, ela é dirigida por um órgão colegiado, cujos membros - um diretor-presidente e três diretores são sabatinados e aprovados pelo Senado Federal. Essa Agência tem sido o principal ente público federal responsável pelo fomento, regulação e fiscalização da indústria 
cinematográfica e audiovisual brasileira em seus diversos segmentos de mercado, com vistas à indução da produção, à distribuição, e à exibição/veiculação de obras audiovisuais brasileiras, sobretudo, produzidas por produtoras independentes.

Tal como a SAv, a referida Agência executa as políticas nacionais para o cinema e o audiovisual formuladas pelo Conselho Superior do Cinema, a exemplo do Plano de Diretrizes e Metas: O Brasil de todos os olhares para todas as telas, aprovado em agosto de 2012 e norteador das ações da Ancine para o desenvolvimento da indústria audiovisual, até o ano de 2020.

No que concerne ao sistema de gestão federal de políticas públicas para audiovisual, a Ancine, ao longo desses 15 anos de trajetória institucional, consolidou-se como agência de regulação e de desenvolvimento de referência na administração pública brasileira, contando com quadro de cerca de 360 servidores efetivos ${ }^{20}$; além de possuir um escopo regulatório bem delineado em relação aos mercados de cinema e de TV Paga, e em ampliação sobre emergentes segmentos: como Video on Demand (VoD) e jogos eletrônicos (games).

Concomitante à consolidação institucional, houve o expressivo crescimento de recursos públicos por ela gerenciados e investidos no setor audiovisual brasileiro. $\mathrm{O}$ que em grande medida pode ser explicado pela convergência dos seguintes fatores: FSA, criado pela Lei $\mathrm{n}^{\circ} 11.437$, de 28 dezembro de 2006, regulamentado pelo Decreto $n^{0} 6.299 / 2007$, e aumento na arrecadação da Contribuição para o Desenvolvimento da Indústria Cinematográfica Nacional (CONDECINE), tributo federal que é a principal receita orçamentária do referido fundo público.

Em 2015, segundo a Ancine, o montante arrecadado dessa contribuição ultrapassou $\mathrm{R} \$ 800.000 .000,00$ (oitocentos milhões de reais). (AGÊNCIA NACIONAL DO CINEMA, 2016a). Desse total, o FSA injetou no mercado audiovisual brasileiros mais de R\$ 400.000.000,00 (quatrocentos milhões de reais). (AGÊNCIA NACIONAL DO CINEMA, 2016b). Cenário de investimentos diametralmente oposto ao vivenciado pelo Ministério da Cultura, que passou por profundos cortes orçamentários em 2015, destinando pouco mais de $\mathrm{R} \$ 300.000 .000,00$ (trezentos milhões de reais) para todas suas ações finalísticas. (MIRANDA, 2015). 
Apesar de a Agência ser o principal vetor público de execução das políticas nacionais para o setor audiovisual, com expressivo quadro de servidores especializados e com orçamento de investimentos superior ao do próprio MinC, suas instâncias de decisão institucional, até o momento, não optaram pela tomada de decisão policy making de enfrentar o problema da sub-representação de raça e de gênero como externalidade negativa ${ }^{21}$, cujos efeitos colaterais implicam em elevados custos sociais ao país e, sobretudo, à maioria de nossa população, feminina e negra.

No ano de 2014, quando a pesquisa do GEMAA A Cara do Cinema Nacional: gênero e cor dos atores, diretores e roteiristas dos filmes brasileiros (2002-2012), começou a repercutir na imprensa e a ganhar espaço de debate, foi salutar o posicionamento da Ancine, nessa época. Em resposta à jornalista Isabela Vieira (2014) sobre esses dados de surepresentação, a Agência informou publicamente que "[...] não opina sobre conteúdo dos filmes, elenco ou qualquer coisa do tipo".

Tal reação institucional, identificada aqui como exemplo de nondecison-making ${ }^{22}$, visivelmente, não foi capaz de neutralizar essa importante questão trazida ao conhecimento da sociedade brasileira. Pelo contrário, à medida que o GEMAA atualizava e ampliava o enfoque de seus estudos, estendendo sua análise sobre as maiores bilheterias do cinema nacional entre 1995 e 2016, outras pesquisas $^{23}$ se multiplicaram no campo acadêmico, estimuladas por esses diagnósticos de sub-representação. Ao mesmo tempo, houve o surgimento de novas entidades, tais como a Associação dos Profissionais do Audiovisual Negro (APAN) ${ }^{24}$, a qual tem buscado junto ao setor público, inclusive à Ancine, o diálogo para implementação de ações afirmativas no audiovisual.

A partir desse posicionamento, é possível identificar que o principal ente público de regulação e desenvolvimento desse setor ainda não compreende a sub-representação negra e feminina como problema, isto é, como externalidade negativa. Em sentido contrário, sua ação (ou omissão) regulatória e de fomento diante desse quadro tem concorrido e reforçado a perpetuação de representações enviesadas e deficitárias das vivências de outros grupos sociais que não aqueles hegemônicos em nossa sociedade, naturalizando, portanto, esse espaço de exclusão, sobretudo, da população negra nas telas brasileiras. 
Embora não caiba no escopo dessa pesquisa detalhar as trajetórias históricas que consolidaram eixos frequentemente desconectados de atuação entre Ancine e SAv, explicando os porquês da baixa interlocuçãa ${ }^{25}$ ocorrida entre ambas, especialmente, no que diz respeito à implementação conjunta de ações afirmativas de raça e de gênero, é importante apontar para o equívoco de se perpetuar a clivagem entre atuações institucionais distanciadas, e ainda ancoradas em falsas dicotomias ${ }^{26}$ entre economia e cultura, entre bem simbólico e bem de mercado, entre diversidade cultural (sobretudo de raça e de gênero) e diversidade de agentes econômicos ou de gêneros e formatos. Isso porque toda obra audiovisual é um bem complexo e central tanto para o desenvolvimento da economia da cultura quanto para a difusão das representações simbólicas dos indivíduos e dos mais diversos grupos sociais de um país.

\section{CONCLUSÃO}

De início, vale sublinhar as fronteiras deste artigo para a elaboração de um panorama geral de ações afirmativas de raça e de gênero realizável para o campo do audiovisual brasileiro e que abrangesse as seguintes dimensões da política pública: institucional, processual e material. Indubitavelmente, consideradas as nuances e a complexidade existentes ao se analisar cada uma dessas perspectivas, não foi possível uma abordagem que as exaurisse. No entanto, mostrou-se exequível desenhar um mapa ampliado sobre as ações afirmativas dentro do campo estatal de fomento público ao audiovisual no país, de modo a posicionar o problema da sub-representação de raça e de gênero enquanto eixo central de policy analysis.

É importante destacar também a dinamicidade do tema pesquisado, bem como a pertinência atual (e futura) de continuidade desses estudos. Isso porque, ao fim do desenvolvimento deste trabalho foi possível observar no primeiro semestre de 2017 um novo posicionamento do principal eixo do tripé estatal de desenvolvimento desse setor. A Ancine saiu da posição de nondecision-making (BACHRACHB; BARATZ 1962) para então realizar o primeiro Seminário Internacional Mulheres no Audiovisual ${ }^{27}$.

Além disso, a Agência incluiu em seu mais recente Mapa Estratégico e Planejamento Estratégico (Quadriênio 2017-2020), elaborados ao longo do primeiro semestre de 2017, um foco de atuação exclusivamente direcionado a "promover a diversidade de gênero e 
raça na produção das obras audiovisuais brasileiras" ${ }^{28}$. Posicionamento cuja efetividade, ao longo do tempo, deverá ser acompanhada especialmente pelos grupos sociais interessados, como a APAN, e por pesquisadores do campo de políticas públicas.

Consequentemente, os desdobramentos atuais (e futuros) dos posicionamentos de cada um dos eixos do tripé estatal CSC-SAv-Ancine, no que concerne às ações afirmativas como eixo relevante de formulação e de implementação de políticas públicas para o setor audiovisual brasileiro, podem servir de ampla matéria para pesquisa nos campos acadêmico e prático de policy analysis.

\section{REFERÊNCIAS}

AGÊNCIA NACIONAL DO CINEMA. CONDECINE - Valores arrecadados 2006-2016. Rio de Janeiro, 2016a. Disponível em: $<$ https://goo.gl/s8dlffs. Acesso em 15 de abril de 2017.

. Plano de Diretrizes e Metas para o Audiovisual: o Brasil de todos os olhares para todas as telas. 1. ed. Rio de Janeiro, jul. 2013. Disponível em: <https://goo.gl/1UboHp>. Acesso em: 2 abr. 2017.

. Valores totais de Investimento FSA, Recursos Incentivados, Editais, Programas e Prêmios - em Reais (R\$) - 2003 a 2016. Rio de Janeiro, 2016b. Disponível em: <https://goo.gl/LwIsCU>. Acesso em: 15 abr. 2017.

ARAÚJO, J. Z. A força de um desejo: a persistência da branquitude como padrão estético audiovisual. Revista USP, São Paulo, n. 69, p. 72-79, mar./maio 2006. Disponível em: $<$ https://goo.gl/KBt3uV>. Acesso em: 15 out. 2016.

BACHRACH, P.; BARATZ, M. S. Two Faces of Power. The American Political Science Review, [S. 1.], v. 56, p. 947-952, dec. 1962. Disponível em: <https://goo.gl/CBC7nH>. Acesso em: 6 jan. 2017.

BEZERRA, L. A Preservação audiovisual no governo Lula. In: SEMINÁRIO INTERNACIONAL DE POLÍTICAS CULTURAIS, 2010, [S. 1.]. Anais... [S. 1.], 2010. Disponível em:<https://goo.gl/ ENArxf $>$. Acesso em: 2 fev. 2017.

BRASIL. Ministério da Cultura. Novas plataformas do audiovisual são debatidas por Conselho Superior de Cinema. Brasília, DF, 2017. Disponível em:<https://goo. gl/zxnGcZ>. Acesso em: 2 fev. 2017. 
CÂNDIDO, M. R.; CAMPOS, L. A. Infográfico - Raça e Gênero no Cinema Brasileiro (2002-2014). Rio de Janeiro, 2014. Disponível em $<$ https://goo.gl/SJcY93>. Acesso em: 20 ago. 2016.

; FERES JUNIOR, J. A Cara do Cinema Nacional: gênero e raça nos filmes nacionais de maior público (19952014). Textos para discussão, Rio de Janeiro, n. 13, p. 1-20, 2016. Disponível em: <https://goo.gl/E9Cxj4>. Acesso em: 5 jan. 2017.

CARVALHO, N. dos S. Esboço para uma história do negro no cinema brasileiro. In: DE, J. (Org.). Dogma Feijoada: o Cinema Negro brasileiro. São Paulo: Imprensa Oficial, 2005. p. 17-101. v. 1.

DA-RIN, S. Dez anos de políticas públicas para o audiovisual brasileiro. Revista Observatório Itaú Cultural, São Paulo, n. 10, set./ dez. 2010. Disponível em:<https://goo.gl/FBfw8u >. Acesso em: 2 mar 2017.

DYE, T. D. Understanding Public Policy. Englewood Cliffs, N.J.: PrenticeHall. 1984.

EASTON, D. An approach to the analysis of political systems. World Politics, [S. 1.], v. 9, n. 3, pp. 383-400, apr. 1957. Disponível em: $<$ https://goo.gl/qjB3f7>. Acesso em: 1 mar. 2017.

FAUSTINI, M. Yasmin Tainá. Jornal O Globo, Rio de Janeiro, 2015. Caderno de Cultura. Disponível em $<\mathrm{https} / /$ goo.gl/Mk4Czz $>$. Acesso em: 20 jun. 2016.

FERREIRA, V. Viva a nós e as águas: representação das mulheres negras no cinema. Brasília, DF, 2015. Palestra proferida no Festival Latinidades 2015. Disponível em < https://goo.gl/3uQM9N $>$. Acesso em: 25 out. 2016.

FREY, K. Políticas Públicas: um debate conceitual e reflexões referentes à prática da análise de políticas públicas no Brasil. Planejamento e Políticas Públicas, Brasília, DF, n. 21, jun. 2000. Disponível em: $<$ https://goo.gl/QhBucm>. Acesso em: 2 mar. 2017.

GELEDÉS - INSTITUTO DA MULHER NEGRA. Centro Feminista de Estudos e Assessoria. Guia de enfrentamento do racismo institucional. São Paulo, 2013. Disponível em:<https://goo.gl/ kb2K7a>. Acesso em: 2 abr. 2017.

IKEDA, M. Estado e cinema no início do século XXI: características de formação da ANCINE. Rio de Janeiro: Fundação Casa de Rui 
Barbosa, 2011. Disponível em: $<$ https://goo.gl/XF3cJQ $>$. Acesso em: 29 out. 2016.

MARSON, M. I. Para entender a retomada: Cinema e Estado no Brasil nos anos 1990. Revista Observatório Itaú Cultural, São Paulo, n. 10, set./dez. 2010. Disponível em: <https://goo.gl/oXrQoh>. Acesso em: 2 mar. 2017.

MEAD, L. M. Public policy: vision, potential, limits. Policy currents, [S. 1.], n. 5, p. 1-4, 1995. Disponível em: <https://goo.gl/6HYsS7>. Acesso em: 1 mar. 2017.

MIRANDA, A. Ministério da Cultura terá orçamento menor em relação 2014. O Globo, São Paulo, 2015. Disponível em: <https://goo. gl/uFZZHp >. Acesso em: 16 abr. 2017.

OSÓRIO, R. G. A mobilidade social dos negros brasileiros. Texto para Discussão, Brasília, DF, 2004. Disponível em <https://goo.gl/zhiLzu $>$. Acesso em: 20 fev. 2017.

PITA, M. Associação vai exigir ações afirmativas para negros/as no audiovisual. Carta Capital, São Paulo, 2016. Blog Intervozes. Não paginado. Disponível em: $<$ https://goo.gl/Fv80ND $>$. Acesso em: 2 jan. 2017.

PRADO, L. C. D.; BARRADAS, A. Economia do cinema e do audiovisual: uma resenha. Texto para Discussão, Rio de Janeiro, n. 005, p. 2-31, 2014. Disponível em <https://goo.gl/bWY5Fu>. Acesso em: 16 out. 2016.

RANGEL NETO, M. Apresentação do Programa Brasil de Todas as Telas - Ano 2. Rio de Janeiro: Agência Nacional do Cinema, 2015. Disponível em $<$ https://goo.gl/iwljxe>. Acesso em: 11 nov. 2015.

SILVA, C. de M. F. Mulheres negras e (in)visibilidade: imaginários sobre a intersecção de raça e gênero no cinema brasileiro (1999-2009). Tese (Doutorado) - Universidade de Brasília, Brasília, DF, 2016. Disponível em <https://goo.gl/disLBd>. Acesso em: 20 ago. 2016.

SOUZA, C. Políticas públicas: uma revisão de literatura. Sociologias, Porto Alegre, v. 8, n. 16, p. 20-45, jul./dez. 2006. Disponível em:<https://goo.gl/7TmWjv>. Acesso em: 5 jan. 2017.

VIEIRA, I. Pesquisa revela que mulheres negras estão fora do cinema nacional. Agência Brasil, Rio de Janeiro, 2014. Não paginado. Disponível em:<https://goo.gl/yvXqCZ>. Acesso em: 10 jul. 2014. 


\section{Notas:}

1 A subrepresentação da população negra no campo do audiovisual brasileiro não é fato novo. Cineastas, atores e atrizes, bem como pesquisadores desse setor já produziram um consistente documental crítico a respeito disso, como demonstra o cineasta e pesquisador Noel dos Santos Carvalho (2005) em esboço feito acerca da história do negro no cinema brasileiro. A novidade tem advindo de análises, inclusive quantitativas, sistemáticas e regulares realizadas pelo GEMAA/IESP/UERJ.

2 Interseccionalidade é um termo chave para compreensão das discriminações sofridas por grupos sociais porque revela que distintos tipos de discriminação interagem entre si e assim se potencializam. Ele remonta à década de 1980 e foi influenciado por intelectuais e feministas negras como Angela Davis e Audre Lorde, que têm abordado o tema das desigualdades sociais e dos direitos civis da população negra, sobretudo nos EUA. Sua conceituação é atribuída à Kimberle Crenshaw, cuja investigação teórica, em síntese, trata de como diferentes estruturas de poder e de opressão interagem simultaneamente impactando negativamente a vida de grupos sociais, tornando-os vulneráveis e alvos de discriminação, como o caso das sobreposições entre discriminações de gênero e de raça sofridas por mulheres afro-americanas. (SILVA, 2016)

3 Embora haja divergência quanto à exata conceituação de obras audiovisuais como bem de mérito (merit good), isto é, como aquele capaz de aumentar o bem-estar social, mas cuja viabilidade demandaria a transferência de recursos do resto da economia, através, por exemplo, da indução (fomento) por parte do poder público, é possível identificar nelas os atributos de alto valor cultural, bem como de externalidade positivas. Sobre essa conceituação ver Marcelo Ikeda (2011) e Luiz Carlos Delorme Prado e Ary Barradas (2014).

4 Trata-se de um fundo destinado ao desenvolvimento global da cadeia produtiva do audiovisual brasileiro, que foi criado pela Lei $n^{\circ} 11.437 / 2006$, sendo uma categoria de programação específica do Fundo Nacional de Cultura (FNC).

5 Klaus Frey (2000) descreve aspectos relevantes para compreensão de policy analysis, perfazendo as seguintes dimensões da política: institucional polity que se refere à ordem do sistema político, delimitada pelo sistema jurídico, e à estrutura do sistema político-administrativo; processual politics que tem por referência o processo político, recorrentemente conflituoso, no que se refere à imposição de objetivos, aos conteúdos e às decisões distributivas; e, por fim, material policy que diz respeito aos conteúdos concretos, como a configuração de programas, os problemas técnicos, e ao conteúdo material das decisões.

6 Igualdade material é um conceito jurídico chave na ADPF $n^{\circ} 186$, no qual o Supremo Tribunal Federal (STF) decidiu pela constitucionalidade das cotas étnico-raciais na seleção de estudantes para a Universidade de Brasília (UnB).

7 A referida legislação fixou a reserva de $40 \%$ das vagas de cada um dos cursos das universidades estaduais do Rio de Janeiro para estudantes autodeclarados negros e pardos, representando o marco zero de fixação de cotas étnico-raciais no campo do ensino superior brasileiro.

8 Conferir em PPA 2012-2015 e agenda de planejamento e orçamento nacional para promoção da igualdade racial. (Disponível em: $<\mathrm{https} / / \mathrm{goo} . \mathrm{gl} / \mathrm{k} 38 \mathrm{eqh}>$. Acesso em: 15 jan. 2017).

9 Conferir análise da UnB a respeito do sistema de cotas por ela implementado. (Disponível em: <https://goo.gl/qbJHZU>. Acesso em: 15 out. 2016).

${ }^{10}$ Conferir análise da UERJ a respeito do sistema de cotas por ela implementado. )Disponível em: <https://goo.gl/IMKtJ2>. Acesso em: 20 out. 2016). 
${ }^{11}$ A respeito de processos de nondecison-making para manutenção de status quo, confira Bachrach e Baratz (1962). (Disponível em: <https://goo.gl/XoXBMm>. Acesso em: 6 jan. 2017).

12 "O Brasil é o maior país do mundo em população afrodescendente, fora do continente africano. É o segundo país em população negra depois da Nigéria e o último país a abolir a escravidão negra. Foi também o país que mais importou africanos para serem escravizados." (INSTITUTO BRASILEIRO DE GEOGRAFIA E ESTATÍSTICA; INSTITUTO DE PESQUISAS ECONÔMICA APLICADA, 2010 apud GELEDÉS - INSTITUTO DA MULHER NEGRA, 2013).

13 Conferir na apresentação do Programa Brasil de Todas as Telas - Ano 2, realizado pelo então Diretor Presidente da Ancine Manoel Rangel Neto (2015).

14 A gestão pública das políticas audiovisuais está ancorada na interação entre os eixos desse tripé desenhado, tanto política quanto tecnicamente, ao longo da primeira década de 2000: "A rearticulação da ação federal foi, então, planejada a partir de três instituições: o Conselho Superior do Cinema como órgão superior, a Agência Nacional do Cinema, como agência reguladora e de desenvolvimento, e a Secretaria do Audiovisual do MinC, responsável pelas ações relativas à cultura cinematográfica e audiovisual e à inovação de linguagem. A chave desse sistema é o Conselho Superior do Cinema. Pensado como órgão de definição das políticas e composto de forma paritária por nove Ministros e por representantes da sociedade civil e da indústria audiovisual, o CSC surgiu como um organismo democrático de debate e formulação de diretrizes, entendido como o lugar em que se estabelece a legitimidade das políticas audiovisuais". (AGÊNCIA NACIONAL DO CINEMA, 2012, p. 24).

${ }^{15}$ Os representantes externos são nomeados para mandatos de 2 (dois) anos, conforme dispõe o $\S 5^{\circ}$ do art. $2^{\circ}$ do Decreto $n^{\circ} 4.858$ de 13 de outubro de 2003 .

${ }^{16}$ Conforme é possível avaliar a partir da seguinte notícia Novas plataformas do audiovisual são debatidas por Conselho Superior do Cinema, oficialmente divulgada pelo Ministério da Cultura (BRASIL, 2017).

${ }^{17}$ Como assinala Marson (2009), a história do cinema brasileiro é uma história feita de ciclos. Em março de 1990, o Governo Collor, imbuído de uma concepção neoliberal de que a cultura é um problema de mercado e de que o Estado não possui responsabilidades sobre isso, extinguiu as políticas culturais vigentes por meio de um pacote de desmonte que incluiu: a revogação da única lei de incentivo fiscal para investimentos em cultura, a chamada Lei Sarney (Lei n ${ }^{\circ} 7.505 / 86$ ); a extinção de autarquias, fundações e empresas públicas federais como a Fundação do Cinema Brasileiro (FCB), do Empresa Brasileira de Filmes (Embrafilme) e o Conselho de Cinema (Concine); e a dissolução do MinC, transformando-o em secretaria do Ministério da Educação.

${ }^{18}$ Conferir pronunciamento do Ministro da Cultura Gilberto Gil, em razão do lançamento do Programa Brasileiro de Cinema e de Audiovisual, em 13 de outubro de 2003. (Disponível em: <https://goo.gl/WBApwa>. Acesso em: 2 fev. 2017).

${ }^{19}$ Cumpre destacar o papel do III Congresso Brasileiro de Cinema na criação da Ancine, realizado em Porto Alegre, em julho de 2000, a partir do qual foi criado o Grupo Executivo de Desenvolvimento da Indústria do Cinema (GEDIC), responsável por encaminhar ao Governo FHC a proposta de criação de um órgão de regulação, normatização e fiscalização da produção e comercialização de bens e serviços audiovisuais. (DA-RIN, 2010).

${ }^{20}$ Cargos de provimento efetivo na Ancine: 150 Especialistas em Regulação da Atividade Cinematográfica e Audiovisual; 64 Técnicos em Regulação da Atividade Cinematográfica e Audiovisual; 70 Analistas Administrativos, 76 Técnicos Administrativos. Conferir em: Anexo I da Lei no 10.871/2004. (Disponível em: < https://goo.gl/yrYKu7>. Acesso em: 16 abr. 2017).

${ }^{21}$ Sobre externalidades na Teoria Econômica, Paul Krugman (2007). 
${ }^{22}$ Sobre o conceito de nondecison-making na literatura especializada, conferir em Bachrachb e Baratz (1962).

${ }^{23}$ Uma das pesquisas de referência que partem dos dados gerados pelo GEMAA sobre a subrepresentação feminina e negra no cinema brasileiro é a tese Mulheres negras e (in) visibilidade: imaginários sobre a intersecção de raça e gênero no cinema brasileiro (19992009) da pesquisadora Conceição de Maria Ferreira Silva (2016).

${ }^{24}$ Conforme o Boletim da APAN, de 7 de abril de 2017, publicado em sua página no Facebook, houve interlocução junto à Ancine durante o evento Rio Content Market 2017.

${ }^{25}$ A baixa interlocução entre SAv e Ancine já foi destacada pelo ex-secretário do audiovisual (SAv/MinC), o cineasta Silvio Da-Rin (2010, p. 98): “[...] as duas instituições foram reunidas no Sistema MinC, mas carecem de articulação mínima entre suas ações. Não é exagero dizer que as formulações e ações do ministério para o setor audiovisual correspondem, na prática, a um corpo bicéfalo, cada órgão desenvolvendo suas próprias políticas e programas. As tentativas recentes da SAv de criação de uma instância de coordenação com a agência não encontraram eco e malograram. Esse é um ponto vital, a ser superado por um próximo governo, no que concerne à arquitetura institucionalgovernamental para o setor".

${ }^{26}$ Sobre a relevância de uma literatura não ortodoxa acerca da indústria do audiovisual que agregue relevância comercial/econômica e papel simbólico/cultural das obras audiovisuais, conferir em Prado e Barradas (2014).

${ }^{27}$ Seminário Internacional Mulheres no Audiovisual, realizado pela Ancine, em 30 de março de 2017. (Disponível em: <https://goo.gl/zHZxCB>. Acesso em: 2 abr. 2017).

${ }^{28}$ Mapa Estratégico da Ancine para o próximo quadriênio 2017-2020. (Disponível em: $<$ https://goo.gl/aqrLwx>. Acesso em: 5 maio 2017). 